\title{
The activity of phagocytic cells after in vivo administration of propentofylline in mice
}

\author{
MARIANNA SZCZYPKA, MAGDALENA LIS, AGNIESZKA SUSZKO, ALEKSANDRA PAWLAK, \\ BOŻENA OBMIŃSKA-MRUKOWICZ
}

Department of Biochemistry, Pharmacology and Toxicology, Faculty of Veterinary Medicine, Wrocław University of Environmental and Life Sciences, Poland

\begin{abstract}
Propentofylline, a phosphodiesterase (PDE) inhibitor, increases the intracellular level of cyclic nucleotides (cAMP and cGMP) and, in consequence, can change the activity of many cells, including immune cells. The studies were conducted on female Balb/c mice (8 weeks of age). Propentofylline was administered orally once or six times at $12 \mathrm{~h}$ intervals at a therapeutic dose of $3 \mathrm{mg} / \mathrm{kg}$. The production of tumor necrosis factor- $\alpha(T N F-\alpha)$, interleukin- $1 \beta(I L-1 \beta)$ and nitric oxide (NO) by resident peritoneal murine macrophages stimulated in vitro with lipopolisaccharide (LPS) from Escherichia coli and the phagocytic activity of granulocytes and monocytes from peripheral blood were determined $12 \mathrm{~h}$ and $24 \mathrm{~h}$ after a single dose or after the last of six doses of propentofylline administration. A temporary decrease in $T N F-\alpha$ synthesis and an increase in $I L-1 \beta$ production were noted $12 \mathrm{~h}$ following a single administration of propentofylline. No effect on the TNF- $\alpha$ and $I L-1 \beta$ release was observed after six doses of the drug applied. Propentofylline, irrespective of the number of subsequent doses applied, did not change the synthesis and release of NO by peritoneal murine macrophages stimulated in vitro with LPS. No effect on the percentage of phagocytosing granulocytes and monocytes was observed after a single administration of propentofylline. However, an increase in the fluorescence intensity of the granulocytes was observed $12 \mathrm{~h}$ and $24 \mathrm{~h}$ after a single dose of the drug administered. Propentofylline administered six times did not change the fluorescence intensity of granulocytes and monocytes, but an increase in the percentage of phagocytosing monocytes was noted. The results obtained in the present study showed that propentofylline administered in vivo did not exhibit an immunosuppressive influence on the activity of phagocytic cells. The changes after propentofylline administration were short-lived and were balanced during the treatment.
\end{abstract}

Key words: propentofylline, phagocytosis, $T N F-\alpha, I L-1 \beta$, nitric oxide.

(Centr Eur J Immunol 2013; 38 (2): 169-174)

\section{Introduction}

Propentofylline (a xanthine derivative) exerts a vasodilatory effect on the peripheral and cerebral microcirculation and has neuroprotective properties. Its action has a beneficial effect in the treatment of vascular or degenerative dementia [1-3]. The neuroprotective effects of propentofylline are associated, among others, with suppressive action on the activation of microglia, e.g. inhibition of tumor necrosis factor- $\alpha$ (TNF- $\alpha$ ), interleukin- $1 \beta$ (IL- $1 \beta$ ) and free radical production by microglia, and with anti-inflammatory properties [1, 3-6]. Propentofylline acts by blocking adenosine transport that leads to elevation of extracellular adeno- sine concentration and also by blocking adenosine receptors $[4,7]$. Propentofylline also shows the inhibitory effect on phosphodiesterase (PDE) activity. Phosphodiesterase, an enzyme responsible for the hydrolysis of cyclic nucleotides, is expressed in various mammalian tissues and cells in multiple forms [8]. There are at least 11 families of PDE, which are characterized, among others, by their substrate specificity [8]. Propentofylline mainly inhibits PDE4 and, in this way, increases the intracellular cAMP level (PDE3 inhibition is significantly less potent than PDE4 block) [9]. It was found that propentofylline enhances not only the cAMP level but also causes an increase in the intracellular level of cGMP due to inhibition of PDE2 and PDE5 activity [2, 9].

Correspondence: Marianna Szczypka, Department of Biochemistry, Pharmacology and Toxicology, Faculty of Veterinary Medicine, Wrocław University of Environmental and Life Sciences, Norwida 31, 50-375 Wrocław, Poland, tel. +48 713205403 , fax +48 713205455 , e-mail: marianna.szczypka@up.wroc.pl 
It was found that the reduction of neuronal damage in the central nervous system by propentofylline is related to the increase in the intracellular cGMP level [10, 11]. The PDE inhibitors increase the intracellular level of cAMP and/or cGMP and, in consequence, change the activity of many cells, including phagocytic cells. Currently, the PDE4 family is the major target for the drugs affecting the immune system [8, 12-14]. Thus, the purpose of this study was to determine the influence of propentofylline, which inhibits principally PDE4, on the activity of phagocytic cells such as peritoneal macrophages and peripheral blood granulocytes and monocytes after in vivo administration in mice.

\section{Material and methods}

\section{Animals}

The studies were conducted on female Balb/c mice (8 weeks of age), each weighing 20-22 g. The mice were obtained from the Breeding Center of Laboratory Animals at the Institute of Occupational Medicine, Łódź, Poland. The principles of laboratory animal care (NIH publication No. 86-23, revised 1985) as well as the specific national laws on the protection of animals were followed. The study protocol was approved by the Local Ethics Committee in Wrocław, Poland (No. 128/2010).

\section{Drug and treatment}

Propentofylline (in substance, Sigma) was dissolved in distilled water and administered to mice orally (by stomach tube) once or six times at $12 \mathrm{~h}$ intervals at a therapeutic dose of $3 \mathrm{mg} / \mathrm{kg}$. At the same time, the control mice received distilled water instead of propentofylline. The volume of each dose was $0.1 \mathrm{ml}$ per animal. Each experimental group consisted of 8 mice.

\section{Measurements}

The following parameters were measured: (i) the synthesis and release of TNF- $\alpha, \mathrm{IL}-1 \beta$ and nitric oxide (NO) in the culture supernatants of the resident peritoneal murine macrophages stimulated in vitro with lipopolisaccharide (LPS) from Escherichia coli (055:B5, Sigma); and (ii) the phagocytic activity of peripheral blood monocytes and granulocytes. These parameters were determined $12 \mathrm{~h}$ and $24 \mathrm{~h}$ after a single dose or after the last of six doses of propentofylline administration.

\section{Tumor necrosis factor- $\alpha$, interleukin- $1 \beta$ and nitric oxide production assay}

The mice were killed by cervical dislocation after anesthesia with halothane (Narcotan, Zentiva, Prague, Czech Republic). Peritoneal exudate macrophages were harvested in sterile ice-cold phosphate buffered saline solution PBS (Institute of Immunology and Experimental Therapy, Wrocław, Poland) supplemented with antibiotics: penicillin
$10 \mathrm{U} / \mathrm{ml}$ and streptomycin $1 \mu \mathrm{g} / \mathrm{ml}$ (Penicillin-Streptomycin Solution Stabilised, Sigma). After centrifugation (375 g, $10 \mathrm{~min}$ ), the cells were suspended in RPMI-1640 medium (Institute of Immunology and Experimental Therapy, Wrocław, Poland) supplemented with $10 \mathrm{mM}$ HEPES (Sigma), 2 mM L-glutamine (Sigma), 10\% fetal bovine serum - FBS (Sigma), and antibiotics (penicillin $10 \mathrm{U} / \mathrm{ml}$ and streptomycin $1 \mu \mathrm{g} / \mathrm{ml}$, Sigma). After the wash, the cells were adjusted to a concentration of $1.5 \times 10^{6}$ cells $/ \mathrm{ml}$, dispensed in $100 \mu \mathrm{l}$ volumes in a 96 -well flat bottom plate (TPP, Switzerland). After incubation $\left(3 \mathrm{~h}\right.$, at $37^{\circ} \mathrm{C}$ in normal atmosphere with $5 \% \mathrm{CO}_{2}$ ) the medium with non-adherent cells was replaced by the same fresh medium. The incubation was continued for a further $20 \mathrm{~h}$ and the medium was replaced by the medium without FBS, but containing LPS from E. coli, serotype 055:B5 (Sigma) at a concentration of $2.5 \mu \mathrm{g} / \mathrm{ml}$. The supernatants were removed after $24 \mathrm{~h}$ of incubation and stored at $-70^{\circ} \mathrm{C}$.

The levels of TNF- $\alpha(\mathrm{pg} / \mathrm{ml})$ and IL- $1 \beta(\mathrm{pg} / \mathrm{ml})$ in macrophage culture supernatants were determined using commercial kits: Quantikine ELISA Kit Mouse TNF- $\alpha$ (R\&D Systems, Minneapolis, USA; lot: 294959) and Quantikine ELISA Kit Mouse IL-1 $\beta / I L-1 F 2$ (R\&D Systems, Minneapolis, USA; lot: 298174), respectively. The procedures were carried out according to the manufacturer's instructions (at wavelength of $450 \mathrm{~nm}$ with a wavelength correction of $570 \mathrm{~nm}$ ).

The level of NO in macrophage culture supernatants was measured as nitrite [15]. $50 \mu \mathrm{l}$ aliquots of macrophage supernatant were incubated with $50 \mu 1$ of Griess reagent: $1 \%$ sulfanilamide (Sigma), 0.1\% N-(1-Naphthyl)-ethylenediamine dihydrochloride (Sigma) and $2 \% \mathrm{H}_{3} \mathrm{PO}_{4}$ (Chempur, Piekary Śląskie, Poland) at room temperature for $5 \mathrm{~min}$. The absorbency of the samples was measured using a microplate autoreader at $550 \mathrm{~nm}$ wavelength. The concentration of the nitrite $(\mathrm{nM})$ in the samples was calculated by reference to a standard dilution of sodium nitrite (Chempur, Piekary Śląskie, Poland) ranging from 0.3125 to $20 \mathrm{nM}$. Each sample was tested in duplicate.

\section{Phagocytic activity}

The mice were anesthetized with halothane (Narcotan, Zentiva, Prague, Czech Republic). The blood samples were collected from retro-ocular arteries to the tubes containing heparin anticoagulant (Equimed, Kraków, Poland). Then, the mice were killed by cervical dislocation. Commercial Phagotest (lot: 1323213148) was used according to the manufacturer's instructions (ORPEGEN Pharma, Heidelberg, Germany). Fluorescence was analysed using a flow cytometer (FACS Calibur, Becton-Dickinson Biosciences) with a CellQuest 3.1f. software. The Phagotest allows to measure the percentage of phagocytosing granulocytes and monocytes (ingestion of one or more bacteria per cell) and their mean fluorescence intensity (individual phagocytic activity - the number of bacteria per cell). 
Table 1. The phagocytic activity of peripheral blood granulocytes and monocytes after single or six times administration of propentofylline at a dose of $3 \mathrm{mg} / \mathrm{kg}$ in mice. The mean value $(n=8)$ and standard deviation

\begin{tabular}{lcccc}
\hline Group & Hours & \multicolumn{2}{c}{ Granulocytes } & Monocytes \\
\cline { 2 - 5 } & & $\begin{array}{c}\text { \% of phagocytosing } \\
\text { cells }\end{array}$ & $\begin{array}{c}\text { mean fluorescence } \\
\text { intensity }\end{array}$ & $\begin{array}{c}\text { \% of phagocytosing } \\
\text { cells }\end{array}$ \\
\hline intensity & $57.94 \pm 6.63$ & $21.72 \pm 3.65$ \\
\hline $\begin{array}{l}\text { propentofylline } \\
1 \times 3 \mathrm{mg} / \mathrm{kg}\end{array}$ & 12 & $74.56 \pm 4.57$ & $43.96 \pm 5.54$ & $55.42 \pm 7.13$ \\
\hline $\begin{array}{l}\text { propentofylline } \\
1 \times 3 \mathrm{mg} / \mathrm{kg}\end{array}$ & 24 & $77.94 \pm 5.26$ & $52.92 * * \pm 3.90$ & $56.08 \pm 7.09$ \\
\hline $\begin{array}{l}\text { control group } \\
\text { propentofylline } \\
6 \times 3 \mathrm{mg} / \mathrm{kg}\end{array}$ & 12 & $71.17 \pm 5.21$ & $50.32 * \pm 2.54$ & $45.68 \pm 5.19$ \\
\hline $\begin{array}{l}\text { propentofylline } \\
6 \times 3 \mathrm{mg} / \mathrm{kg}\end{array}$ & 24 & $74.14 \pm 6.84$ & $35.58 \pm 4.46$ & $52.73 \pm 8.63$ \\
\hline
\end{tabular}

$* p<0.05$ as compared to the control group

$* * p<0.01$ as compared to the control group

\section{Statistical analysis}

The data obtained in this study were analyzed statistically using a $t$-Student test. The differences were considered significant at $p<0.05$. The data were analyzed with Statistica 9.1 software.

\section{Results}

The effects of propentofylline on tumor necrosis factor- $\alpha$, interleukin- $1 \beta$ and nitric oxide production by murine peritoneal macrophages

The single administration of propentofylline temporarily decreased the synthesis and release of TNF- $\alpha$. This effect was observed only $12 \mathrm{~h}$ following the drug administration. A temporary increase in IL- $1 \beta$ synthesis was noted $12 \mathrm{~h}$ following a single dose of propentofylline applied. No effect on TNF- $\alpha$ and IL- $1 \beta$ release was observed after six times of the drug exposure. Propentofylline, irrespective of the number of subsequent doses applied, did not change the synthesis and release of NO by peritoneal murine macrophages stimulated in vitro with LPS.

\section{The effects of propentofylline on phagocytic activity of granulocytes and monocytes}

No effect on the percentage of granulocytes and monocytes showing phagocytosis was observed after a single administration of propentofylline. But an increase in the fluorescence intensity of granulocytes was observed $12 \mathrm{~h}$ and $24 \mathrm{~h}$ after a single dose of the drug administered. Propentofylline administered six times did not change the fluorescence intensity of granulocytes and monocytes, but an increase in the percentage of phagocytosing monocytes was noted $24 \mathrm{~h}$ after the last dose of the drug applied.

\section{Discussion}

Monocytes and macrophages differ in the PDE isoenzyme profile. In human monocytes, PDE4 is the predominant cAMP-hydrolyzing enzyme [16]. During differentiation of monocytes to macrophages, PDE4 activity decreases, while the activity of PDE1 and PDE3 augments [16]. Phosphodiesterase 2 is also expressed in macrophages [8]. In human neutrophils, the predominant PDE family is PDE4, the activity of PDE5 was also found, but to a lesser extent [17]. Previous studies reported that nonselective and selective PDE inhibitors suppress TNF- $\alpha$ release from monocytes and macrophages, but most of these studies were conducted in vitro [16, 18-21]. The most significant inhibitory effects were observed after the use of selective PDE4 inhibitors (i.e. rolipram) [12, 14, 16, 18, 20-22]. Gantner et al. [16] reported that TNF- $\alpha$ production by monocytes and macrophages is differentially regulated by PDE inhibitors. The suppression of TNF- $\alpha$ release was more evident in human monocytes as compared to macrophages. This effect can be related with a different PDE profile in these cells. Kambayashi et al. [22] conducted an in vivo study and reported that in endotoxemic mice, rolipram suppressed TNF- $\alpha$ release ( $3 \mathrm{~h}$ after i.p. drug administration at a dose of $20 \mathrm{mg} / \mathrm{kg}$ ). It was found that propentofylline also decreased TNF- $\alpha$ production by macrophages [23] and monocytes [24] in in vitro assays. Interestingly, Jung et al. [23] reported that propentofylline at a very low concentration $(0.01 \mathrm{nM}, 1 \mathrm{nM})$ exhibited a weak stimulating effect on TNF- $\alpha$ synthesis.

In the present experiments, the suppressive effect of propentofylline on TNF- $\alpha$ release was noted. But it was temporary, observed only $12 \mathrm{~h}$ after a single dose of the drug applied. At the same time point, a temporary increase in IL-1 $\beta$ 

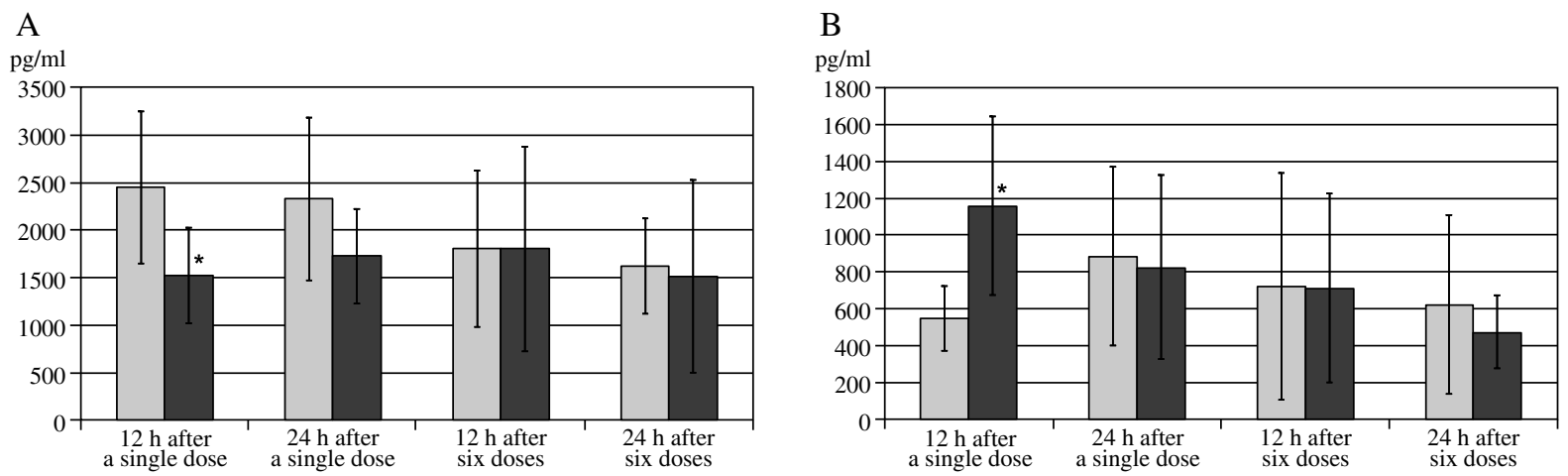

C

$\mathrm{pg} / \mathrm{ml}$
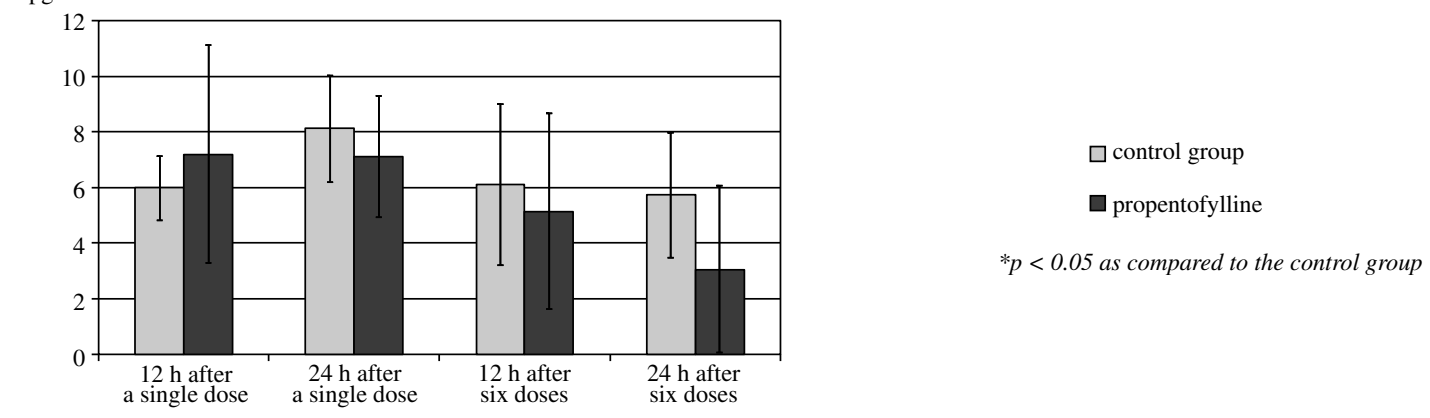

Fig. 1. The tumor necrosis factor $\alpha(\mathrm{A})$, interleukin $1 \beta$ (B) and nitric oxide (C) production by murine peritoneal macrophages stimulated in vitro with lipopolisaccharide from $E$. coli after single or six times administration of propentofylline at a dose of $3 \mathrm{mg} / \mathrm{kg}$. The mean value $(n=8)$ and standard deviation

production was noted. The similar influence of PDE inhibitors on IL-1 $\beta$ synthesis was observed in our previous study conducted in vivo after a single dose of aminophylline (nonselective PDE inhibitor), milrinone (selective PDE3 inhibitor) and sildenafil (selective PDE5 inhibitor) [25]. On the other hand, it was found that PDE inhibitors decreased the IL-1 $\beta$ production, but these studies were conducted in vitro [18, 20, 21]. Miki and Miki [26] in the study conducted in vitro found that propentofylline at a concentration of 1.0 to $3.0 \mathrm{mmol} / 1$ slightly enhanced IL- $1 \beta$ synthesis by human peripheral blood mononuclear cells (PBMCs). In the same study, in culture of PBMCs stimulated in vitro with streptococcal preparation (OK-432), the production of IL-1 $\beta$ was markedly suppressed by propentofylline [26].

In the present study, a difference between the effect of propentofylline on TNF- $\alpha$ and IL- $1 \beta$ production was found. These results are in accordance with the data from another study, which showed that selective PDE4 inhibitors (rolipram and nitraquazone) exerted a more potent inhibitory effect on TNF- $\alpha$ synthesis than on IL-1 $1 \beta$ production [18].

The present experiment showed that propentofylline did not affect the killing activity of peritoneal macrophages measured by NO production. We have previously found that PDE inhibitors administered in vivo at therapeutic doses temporarily augmented NO synthesis. This increase was observed $12 \mathrm{~h}$ after a single dose of milrinone or sildenafil and $12 \mathrm{~h}$ after the last of five doses of aminophylline or milrinone [25]. Nemeth et al. [19], in the study conducted in vivo, demonstrated that theophylline (nonselective PDE inhibitor) or amrinone (selective PDE3 inhibitor), administered intraperitoneally at a dose of $100 \mathrm{mg} / \mathrm{kg}$, caused a decrease in plasma nitrite/nitrate levels (as breakdown products of NO). But the doses of these drugs were much higher than the dose of propentofylline used in the present experiments. In the in vitro assay, Beshay et al. [27] reported that rolipram (selective PDE4 inhibitor) and pentoxifylline (nonselective PDE inhibitor) reduced NO release by murine peritoneal macrophages and RAW 264.7 cells. However, pentoxifylline was less potent and exhibited this effect at a concentration about 40 times higher as compared to rolipram.

The results obtained in the present study showed that propentofylline had only a little effect on the phagocytic activity of peripheral blood granulocytes and monocytes. In our previous study we found a similar effect for aminophylline [25]. When administered i.m. to mice at a single therapeutic dose of $20 \mathrm{mg} / \mathrm{kg}$, this drug did not affect the phagocytic activity and oxidative burst in blood leukocytes. 
However, five times daily aminophylline administration caused a transient stimulatory effect on these parameters. On the other hand, Banati et al. [28] reported that propentofylline at a concentration of $50 \mu \mathrm{M}$ (considered to be equivalent to therapeutic levels) inhibited concanavalin A-induced production of reactive oxygen intermediates by peritoneal macrophages. Similarly, Zhang and Fredholm [29] demonstrated the inhibitory influence of propentofylline on neutrophil $\mathrm{H}_{2} \mathrm{O}_{2}$ production. However, it should be stressed that, in contrast to the present study, the latter two studies were conducted in vitro. Such conditions may not always reflect the complexity of cellular interactions in vivo.

In summary, the results obtained in the present study showed that propentofylline administered in vivo did not exhibit an immunosuppressive influence on the activity of phagocytic cells such as peritoneal macrophages and peripheral blood monocytes and granulocytes. The changes after propentofylline administration were short-lived and were balanced during the treatment.

The authors declare no conflict of interest. The authors alone are responsible for the content and writing of the paper.

\section{References}

1. Rudolphi KA, Schubert P (1997): Modulation of neuronal and glial cell function by adenosine and neuroprotection in vascular dementia. Behav Brain Res 83: 123-128.

2. Schubert P, Morino T, Miyazaki H, et al. (2000): Cascading glia reactions: a common pathomechanism and its differentiated control by cyclic nucleotide signaling. Ann N Y Acad Sci 903: 24-33.

3. Sweitzer S, De Leo J (2011): Propentofylline: glial modulation, neuroprotection, and alleviation of chronic pain. Handb Exp Pharmacol 200: 235-250.

4. Parkinson FE, Rudolphi KA, Fredholm BB, et al. (1994): Propentofylline: a nucleoside transport inhibitor with neuroprotective effects in cerebral ischemia. Gen Pharmacol 25: 1053-1058.

5. Schubert P, Ogata T, Rudolphi K, et al. (1997): Support of homeostatic glial cell signaling: a novel therapeutic approach by propentofylline. Ann N Y Acad Sci 826: 337-347.

6. Si Q, Nakamura Y, Ogata T, et al. (1998): Differential regulation of microglial activation by propentofylline via cAMP signaling. Brain Res 812: 97-104.

7. Fredholm BB, Fastbom J, Kvanta A, et al. (1992): Further evidence that propentofylline (HWA 285) influences both adenosine receptors and adenosine transport. Fundam Clin Pharmacol 6: 99-111.

8. Bender AT, Beavo JA (2006): Cyclic nucleotide phosphodiesterases: molecular regulation to clinical use. Pharmacol Rev 58: 488-520.

9. Meskini N, Némoz G, Okyayuz-Baklouti I, et al. (1994): Phosphodiesterase inhibitory profile of some related xanthine derivatives pharmacologically active on the peripheral microcirculation. Biochem Pharmacol 47: 781-788.
10. Kohgami S, Ogata T, Morino T, et al. (2010): Pharmacological shift of the ambiguous nitric oxide action from neurotoxicity to cyclic GMP-mediated protection. Neurol Res 32: 938944.

11. Wirtz-Brugger F, Giovanni A (2000): Guanosine 3',5'-cyclic monophosphate mediated inhibition of cell death induced by nerve growth factor withdrawal and beta-amyloid: protective effects of propentofylline. Neuroscience 99: 737-750.

12. Buenestado A, Grassin-Delyle S, Guitard F, et al. (2012): Roflumilast inhibits the release of chemokines and TNF- $\alpha$ from human lung macrophages stimulated with lipopolysaccharide. Br J Pharmacol 165: 1877-1890.

13. Jin SL, Ding SL, Lin SC (2012): Phosphodiesterase 4 and its inhibitors in inflammatory diseases. Chang Gung Med J 35: 197-210.

14. Kobayashi M, Kubo S, Shiraki K, et al. (2012): Therapeutic potential of ASP3258, a selective phosphodiesterase 4 inhibitor, on chronic eosinophilic airway inflammation. Pharmacology 90: 223-232.

15. Stuehr DJ, Marletta MA (1985): Mammalian nitrate biosynthesis: mouse macrophages produce nitrite and nitrate in response to Escherichia coli lipopolysaccharide. Proc Natl Acad Sci U S A 82: 7738-7742.

16. Gantner F, Kupferschmidt R, Schudt C, et al. (1997): In vitro differentiation of human monocytes to macrophages: change of PDE profile and its relationship to suppression of tumour necrosis factor-alpha release by PDE inhibitors. Br J Pharmacol 121: 221-231.

17. Torphy TJ (1998): Phosphodiesterase isozymes: molecular targets for novel antiasthma agents. Am J Respir Crit Care Med 157: 351-370.

18. Molnar-Kimber K, Yonno L, Heaslip R, Weichman B (1993): Modulation of TNF- $\alpha$ and IL- $1 \beta$ from endotoxin-stimulated monocytes by selective PDE isozyme inhibitors. Agents Actions 39: C77-C79.

19. Németh ZH, Szabó C, Haskó G, et al. (1997): Effect of the phosphodiesterase III inhibitor amrinone on cytokine and nitric oxide production in immunostimulated J774.1 macrophages. Eur J Pharmacol 339: 215-231.

20. Verghese MW, McConnell RT, Strickland AB, et al. (1995): Differential regulation of human monocyte-derived TNF alpha and IL-1 beta by type IV cAMP-phosphodiesterase (cAMPPDE) inhibitors. J Pharmacol Exp Ther 272: 1313-1320.

21. Yoshimura T, Kurita C, Nagao T, et al. (1997): Effects of cAMP-phosphodiesterase isozyme inhibitor on cytokine production by lipopolysaccharide-stimulated human peripheral blood mononuclear cells. Gen Pharmacol 29: 633-638.

22. Kambayashi T, Jacob CO, Zhou D, et al. (1995): Cyclic nucleotide phosphodiesterase type IV participates in the regulation of IL-10 and in the subsequent inhibition of TNF-alpha and IL-6 release by endotoxin-stimulated macrophages. J Immunol 155: 4909-4916.

23. Jung S, Donhauser T, Toyka KV, Hartung HP (1997): Propentofylline and iloprost suppress the production of TNFalpha by macrophages but fail to ameliorate experimental autoimmune encephalomyelitis in Lewis rats. J Autoimmun 10: 519-529.

24. Meiners I, Hauschildt S, Nieber K, Münch G (2004): Pentoxyphylline and propentophylline are inhibitors of TNF-alpha release in monocytes activated by advanced glycation endproducts. J Neural Transm 111: 441-447.

25. Szczypka M, Obmińska-Mrukowicz B (2010): The effects of selective and nonselective phosphodiesterase inhibitors on 
phagocytic cells in mice. Immunopharmacol Immunotoxicol 32: 507-513.

26. Miki S, Miki Y (1991): Differential effects of propentofylline on the production of cytokines by peripheral blood mononuclear cells in vitro. Clin Ther 13: 747-753.

27. Beshay E, Croze F, Prud'homme GJ (2001): The phosphodiesterase inhibitors pentoxifylline and rolipram suppress macrophage activation and nitric oxide production in vitro and in vivo. Clin Immunol 98: 272-279.

28. Banati RB, Schubert P, Rothe G, et al. (1994): Modulation of intracellular formation of reactive oxygen intermediates in peritoneal macrophages and microglia/brain macrophages by propentofylline. J Cereb Blood Flow Metab 14: 145-149.

29. Zhang Y, Fredholm BB (1994): Propentofylline enhancement of the actions of adenosine on neutrophil leukocytes. Biochem Pharmacol 48: 2025-2032. 